\title{
The Device for Low-Cost Measurement of 2D Thermal Distribution
}

\author{
Jiří Mináŕ, Kamil Říha
}

\begin{abstract}
The article describes a specialized device for measurement of thermal distribution of two dimensional surfaces for some applications in medical industry, and mechanical or civil engineering. The device is a substitution of expensive device for this kind of measurement is thermal camera which can be expensive for some application or should have the limitation of non-possibility to read temperature behind a barrier (wall, bandage).

The main goal of this work was to design a device for measurement of thermal distribution on 2D surface for low-cost measuring processes with slow change of temperature and for processes, which do not require high resolution of collected data. The next advantage of presented device is a possibility of temperature measurement behind the barrier.
\end{abstract}

Keywords- 2D Sensor Field, NTC, Temperature Measurement, Thermistor.

\section{INTRODUCTION}

Nowadays, there are many methods of field temperature measurement available on the market. Most of these methods are designed for a non-contact measurement e.g. two-dimensional infrared spectroscopy [1], threedimensional temperature measurement of water using twocolor laser-induced fluorescence (LIF) [2] or CCD (ChargeCoupled Device) or ICCD (Intensified Charge-Coupled Device) sensors [3]. Nevertheless, this kind of measurement device could be expensive for some application or there could be also disadvantage of impossibility of measurement temperature behind the barriers. The most common device, which is used for $2 \mathrm{D}$ temperature field measurement is infrared thermo camera, which can be bought from $\$ 2000$. This can be expensive for some application. Therefore, a low-cost device for these types of measurement is sought. As a basic element for such device simple and cheap sensor: NTC thermistor (Negative Temperature Coefficient) was selected. This sensor is passive electronic component based on conversion of temperature to resistance [4]. The dependence of the resistance of typical thermistor is

$$
R_{T}=A e^{\frac{B}{T}},
$$

Jiri Minar is with Dept. of Telecommunications, Faculty of Electrical Engineering and Communication, Brno University of Technology, Purkynova 118, 61200 Brno, Czech Republic, mail: xminar15@phd.feec.vutbr.cz.

International Journal of Advances in Telecommunications, Electrotechnics, Signals and Systems. where $R_{T}$ is resistance, $A$ is a constant based on geometrical shape and material of thermistor, $B$ is temperature constant based on material of thermistor, and $T$ is thermodynamic temperature.

NTC thermistor has exponential temperature/resistance characteristic. And measurement results can be very imprecise without elimination of this non-linearity. This can be solved with a lookup table (see Chapter IV.) or by inversion function.

As a minimal size of the $2 \mathrm{D}$ temperature field is used sensors matrix with $8 \times 8$ sensors. This size should be sufficient for practical verification of the solution.

\section{SENSOR CHARACTERISTICS}

\section{A. Thermistor}

There is a big variety of NTC thermistors on the market with different size, different toleration or mounting technology, and the price range is from $\$ 0.1$ to $\$ 5$ per sensor.

For experimental device NTC thermistor, form company Betatherm with type number SMD110KJ375J was chosen. Its parameters are described in Table I. This thermistor is built for SMT - Surface Mount Technology. The size of the thermistor is very small $(3.2 \mathrm{~mm} \times 1.6 \mathrm{~mm})$ therefore is suitable for building big sensors array and the price of this sensor is suitable for low cost application. It is about $\$ 0.3$ per sensor.

TABLE I

BETATHERM SMD110KJ375J

\begin{tabular}{ll}
\hline \multicolumn{1}{c}{ Parameter } & \multicolumn{1}{c}{ Value } \\
\hline Operation temperature & $-40^{\circ} \mathrm{C}$ to $+120^{\circ} \mathrm{C}$ \\
Max. load & $400 \mathrm{~mW}$ \\
Resistance at $25^{\circ} \mathrm{C}$ & $10 \mathrm{k} \Omega$ \\
Tolerance & $5 \%$ \\
Dissipation Constant & $3 \mathrm{~mW} /{ }^{\circ} \mathrm{C}$ \\
\hline
\end{tabular}

\section{B. Thermistor Characteristic}

All the sensors used in the two-dimensional field should have the same exponential characteristic. Same exponential characteristic is expected for all thermistors of the same type. The only error in offset is expected, which is given by $5 \%$ tolerance of the thermistor, which can be easily removed only adding or subtracting offset value. This can be solved by implementation into look up table together with linearization of exponential characteristic of thermistor. The shapes of exponential functions of thermistors are same on 
considered temperature operation range $\left(25^{\circ} \mathrm{C}\right.$ to $\left.50^{\circ} \mathrm{C}\right)$. As is seen in Fig. 1, where is the example of two NTC thermistors used in measurement device.

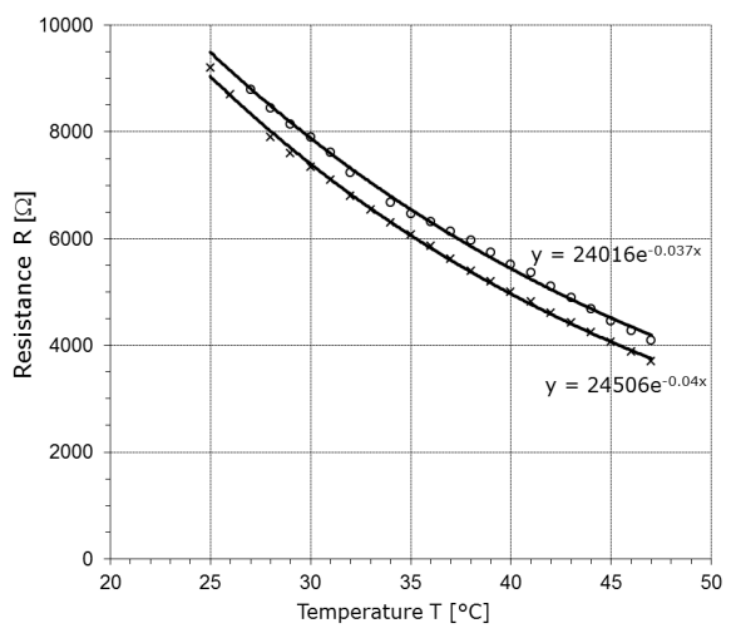

Fig. 1. Example of two NTC thermistors characteristic $R=f(\mathrm{~T})$ with constant current $50 \mu \mathrm{A}$

Measurements of two thermistors were performed in oil fluid, where oil was heat up to $50^{\circ} \mathrm{C}$ and then temperature decrease from $50^{\circ} \mathrm{C}$ to $25^{\circ} \mathrm{C}$. Cool down of thermistor was approximately $1^{\circ} \mathrm{C}$ per 15 seconds. As can be seen from Fig. 1, that temperature is out of tolerance in $25^{\circ} \mathrm{C}$, but this is cause by thermal accumulation of thermistor. Resistance was in tolerance after approx. two minutes. And the values of thermistor were stabilized on values $10100 \Omega$ and $10180 \Omega$, which is $5 \%$ tolerance.

\section{DEVICE REALIZATION}

\section{A. Wheatstone Bridge}

Value of Temperature on sensor is value of resistance of thermistor; therefore temperature is measured indirectly by measuring of voltage. Very good application of this type of measurement is connection of thermistor into Whetstone bridge with differential amplifier (Fig. 2).

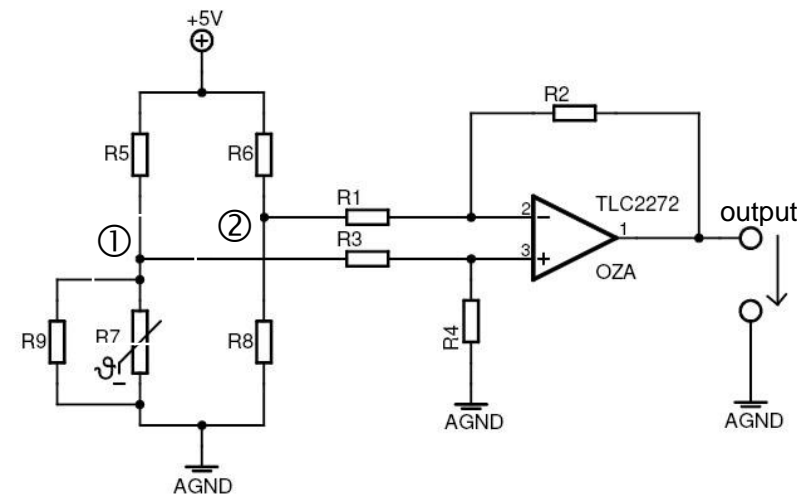

Fig. 2. Wheatstone bridge with parallel connection of thermistor

Device was designed for precision $0.1^{\circ} \mathrm{C}$ and for measuring temperature range from $25^{\circ} \mathrm{C}$ to $45^{\circ} \mathrm{C}$. These parameters were chosen specifically for one of possible use of this device; measuring of skin temperature.

Values of resistance of Wheatstone bridge were designed for mentioned parameters $\left(R_{7}=5 \mathrm{k} \Omega-10 \mathrm{k} \Omega\right.$ parameters of thermistor from Fig. 1) and for precision $0.1{ }^{\circ} \mathrm{C}$ (max. current $\left.I_{\text {max }}=300 \mu \mathrm{A}\right)$.

Bridge is balanced in measurement points' (1) a (2) in Fig. 2. Values of resistors $R_{5}, R_{9}$ are designed to reflect maximum of value of measurement current. Then there are $R_{5}=R_{6}=50 \mathrm{k} \Omega$, and $R_{8}=\left(R_{7}\right.$ in parallel combination with $\left.R_{9}\right)=2200 \Omega$. Resistance $R_{9}$ is added for linearization exponential characteristic of thermistor [4].

Amplifier was chosen TLC2272 from company Linear Technology. This amplifier is of rail-to-rail type (can produce output voltage $V_{\text {out }}$ very close to supply voltage $V_{c c}$. Resistances for setting of differential amplifier were set on these values: $R_{1}=R_{2}=5 \mathrm{k} \Omega$ a $R_{3}=26 \mathrm{k} \Omega$.

Values of resistors were verified in program PSpice that current through thermistor is not higher the $I_{\max }$ (Fig. 3).

Based on toleration analysis of resistors in program PSpise, possible influence of toleration of resistors on temperature error was verified. Resistors $R_{1}-R_{4}$ are not too sensitive to precise value of resistors (Fig. 4).

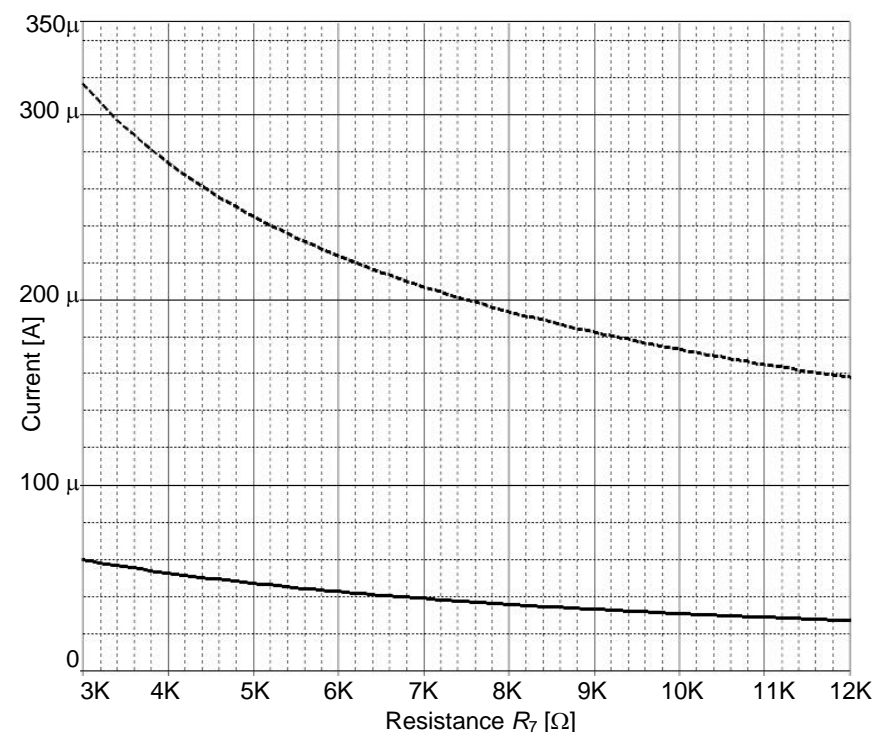

Fig. 3. Current through thermistor $R_{7}$

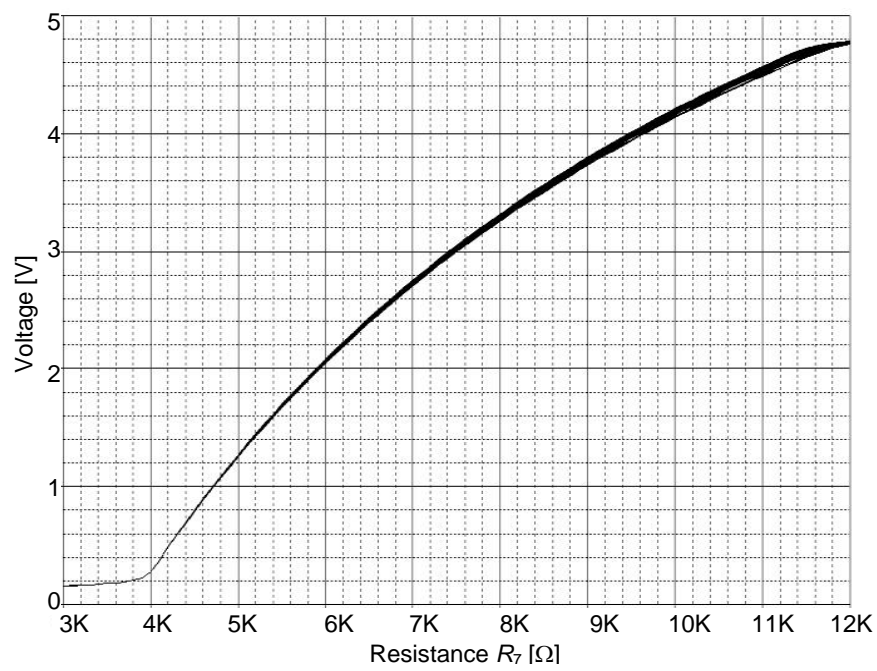

Fig. 4. Toleration analysis for resistors $R_{l}-R_{4}$ with tolerance $1 \%$ 


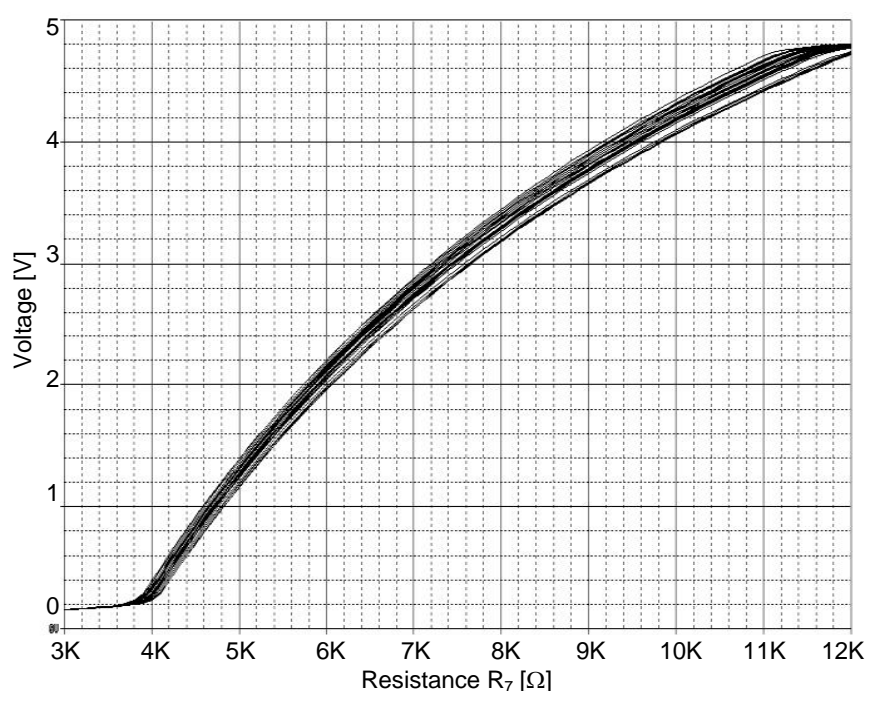

Fig. 5. Toleration analysis for resistors $R_{5}-R_{7}$ and $R_{9}$ with tolerance $1 \%-25$ runs

But resistors $R_{5}-R_{7}$ inside the Wheatstone bridge have to be selected from series with very low tolerance (Fig. 5). Because resistors with $1 \%$ tolerance can cause additional offset error, this means $8^{\circ} \mathrm{C}$ error. For practical realization should be selected resistor from series with tolerance $0.5 \%$ or better or instead of resistor R5 use trimmer for weighting of Wheatstone bridge.

\section{B. Controlling of Sensor matrix}

Matrix of sensors has been designed as square matrix with $8 \times 8$ sensors, therefore switching method was chosen for 64 sensors as an individual connection of thermistors into differential amplifier by multiplexer MC14067B from company ON Semiconductor. This connection ensures that current measurement goes through single switched thermistor (Fig. 6). All thermistors are connected to the ground and only one thermistor is selected. Used multiplexer handle serve 16 sensors, therefore 4 multiplexers have to be used.

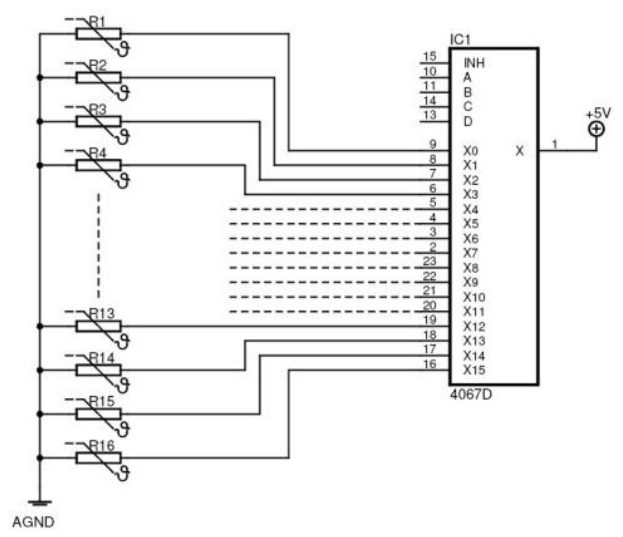

Fig. 6. Switching of thermistor by multiplexer

For controlling and communication with PC microcontroller ATMEL ATmega16 was used. This controller provides necessary functionality for $\mathrm{A} / \mathrm{D}$ conversion and communication. A/D convertor used in ATmega16 has 10-bits resolution and this is enough for temperature range $25^{\circ} \mathrm{C}-45^{\circ} \mathrm{C}$ with toleration $0.1^{\circ} \mathrm{C}$, because change of one bit means that this range is change of $0.02^{\circ} \mathrm{C}$.

\section{EXPERIMENTAL RESULTS}

Due to exponential characteristic of thermistor and offset of thermistor by $5 \%$ toleration, it is essential to calibrate every sensor at whole range of temperature. Exponential characteristic can be linearized by inversion function from eq. (1) or by lookup table. Lookup table was selected due to its modesty to compute power and also for calibration of offset.

For $0.1^{\circ} \mathrm{C}$ precision on all temperature range it is necessary to divide whole range at least to 20 intervals, as is seen in Fig. 7. Each interval is considered as linear.

Calibration should be essential, because non-calibrated sensors can have temperature up to $1^{\circ} \mathrm{C}$. Fig. 8 shows a situation for 3 examples of calibration. First curve considers only 3 calibration points and due to this the temperature error between two these points can be up to $0.9^{\circ} \mathrm{C}$. Second curve demonstrates 5 points calibration with temperature error up to $0.4^{\circ} \mathrm{C}$. And the third curve demonstrates sufficient calibration with 23 points and there is temperature error below $0.1^{\circ} \mathrm{C}$. This calibration should be done in temperature chamber with suitable temperature range and with step $1^{\circ} \mathrm{C}$ per 2 minutes to ensure sufficient heat of thermistor.

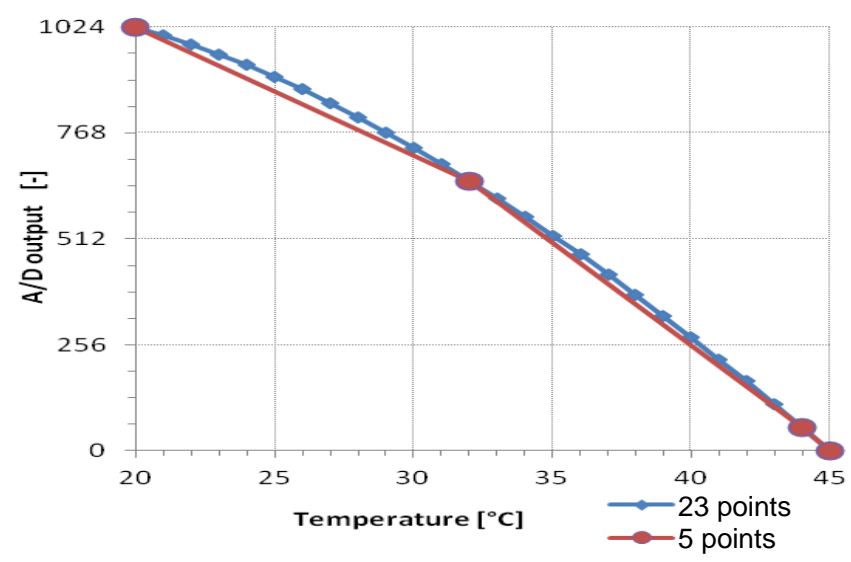

Fig. 7. Conversion characteristic Sample/Temperature for 3-point and 23-points calibration

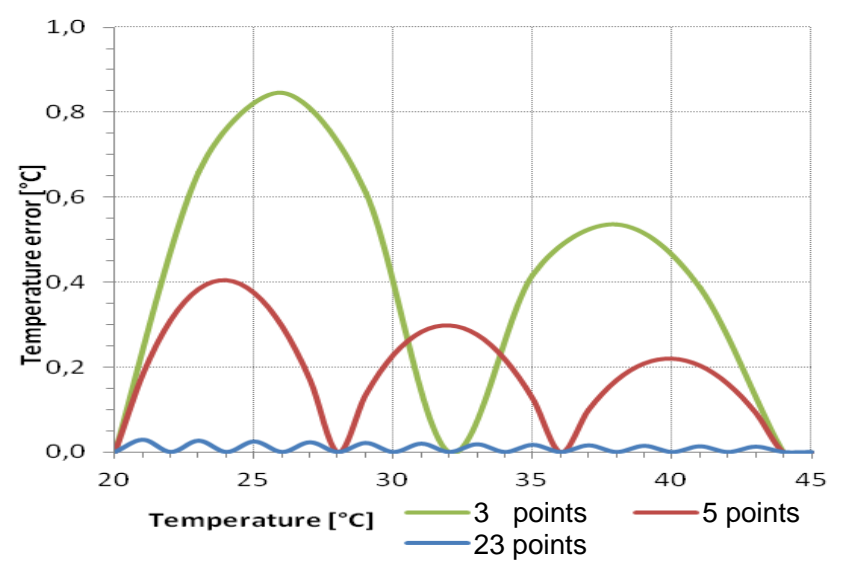

Fig. 8. Temperature error for 3-point, 5-points and 23-points calibration 
a) $8 \times 8$

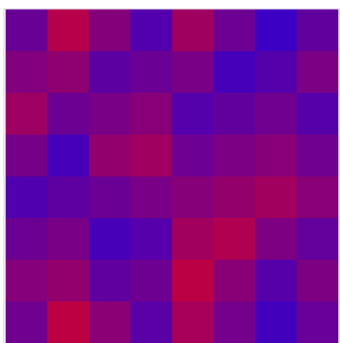

$i=0$ b) $15 \times 15$

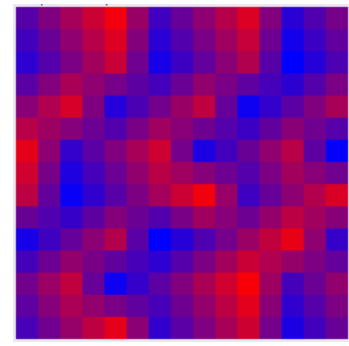

$i=1$ c) $29 \times 29$

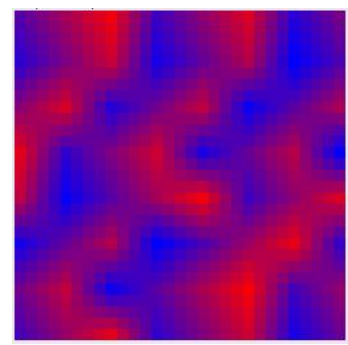

$i=3$ d) $64 \times 64$

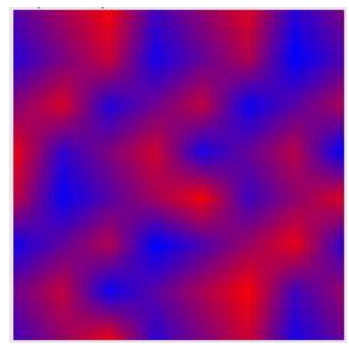

$i=7$

Fig. 9. Interpolation of measurement data - interpolation coefficient $\mathrm{i}$

Visualization of measured values was done as temperature map in $\mathrm{PC}$, where the lowest temperature $\left(25^{\circ} \mathrm{C}\right)$ is of blue color, the highest temperature $\left(45^{\circ} \mathrm{C}\right)$ is red color and the temperatures between the temperature range have the relevant colors from blue - red color range Fig. 9(a) Interpolation from 1 to 7 was used for better interpretation of measured field Fig. 9(b), Fig. 9(c), and Fig. 9(d), where value interpolation coefficient $i$ defined amount of computed values was added between two measured values.

In Fig. 9, there is sample of measured data as a temperature footprint of three fingers as is described in Fig. 10.

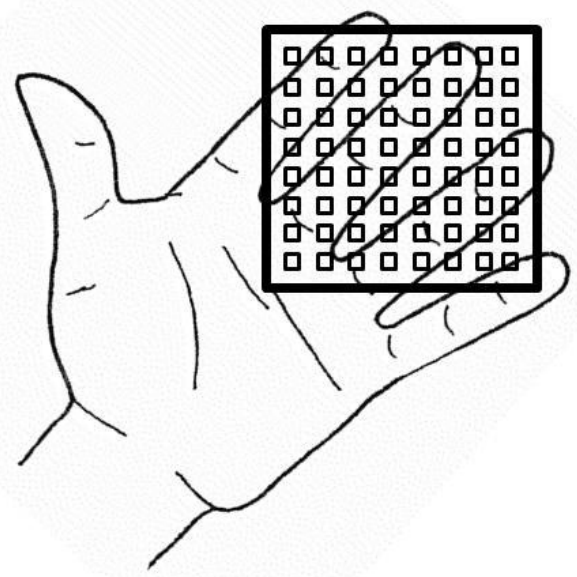

Fig. 10. Experimental measurement of three fingers with matrix of $8 \times 8$ of thermistors

\section{CONCLUSION}

The solution for low cost measurement device based on matrix of NTC thermistor was presented. This device should be used as a cheap substitution of common method of measurement of thermal two-dimensional field e.g. infrared thermo-camera. The proposed solution has price about \$30comparing with price of infrared thermo-camera (starting at \$2.000) is much cheaper. For some application could be advantage that this device could be placed behind solid barrier. This device can be used for measuring the temperature field with slow change of temperature (minutes) and where is not necessary detailed resolution. Relevant application of this solution could be in medical use as e.g. mechanical industry, where the big distance between the sensors is not a problem.

\section{REFERENCES}

[1] Isao Noda, "Two-Dimensional Infrared (2D IR) Spectroscopy Theory and Applications," Appl. Spectrosc. 44, 550-561 (1990)

[2] J. Sakakibara, R. J. Adrian, Whole field measurement of temperature in water using two-color laser induced fluorescence, Experiments in Fluids, Volume 26, Issue 1-2, pp 7-15, 1999

[3] J. Lindén, C. Knappe, M. Richter and M. Aldén, Precision in $2 D$ temperature measurements using the thermographic phosphor BAM, Measurement Science and Technology, Volume 23, Number 8, 2012

[4] Kreidl, Ml. Měřeni teploty: senzory a měřici obvody. 1. vyd. Praha, BEN, 2005. 240 s. ISBN 80-7300-145-4.

Jiri MINAR received BSc. at the Department of Telecommunications at the Faculty of Electrical Engineering and Communication at Brno University of Technology in 2005. He received Ing. (MSc) at the same department in 2007. Now he is a PhD student at the same faculty. The area of his professional interests sensors and digital image processing.

Kamil RIHA received his M.Sc. degree in Electronics \& Communication in 2003 and the Ph.D. degree in 3D Scene Acquisition for AutoStereoscopic Display in 2007. Presently, he is employed at Brno University of Technology, Faculty of Electrical Engineering, Department of Telecommunications, as the academic employee (since 2006). His research interests include in particular areas of digital image processing and electronics. 